\title{
CARNAP AND LEWIS ON THE EXTERNAL WORLD
}

\author{
IVAN FERREIRA DA CUNHA
}

\begin{abstract}
This paper compares the claims about our knowledge of the external world presented by Rudolf Carnap, in the book known as the Aufbau, to those of Clarence Irving Lewis, in Mind and the World-Order. This comparison is made in terms of the opposition to Kantian epistemology that both books establish; the Aufbau is regarded as the peak of the logicist tradition and Mind and the World-Order is taken in continuity with pragmatism. It is found that both books present knowledge of the external world as a consequence of a structural organization of human experience. However, there is an important point of divergence: the concept of verification each author adopts is different, such a concept was even a matter of discussion between Lewis and the Vienna Circle. This paper shows this disagreement but also shows how Carnap changed his point of view in the decade after the Aufbau was published, towards a standpoint which is much closer to Lewis's ideas. In that process, nevertheless, Carnap changed his focus and did not deal with the problem of the external world anymore. This paper also seeks to draw attention to some features of the relation between Carnap and the pragmatist tradition which have only recently started to attract interest.
\end{abstract}

Keywords: Carnap; Lewis; logicism; pragmatism; problem of the external world.

Analytic philosophy and pragmatism can be seen as philosophical traditions that had a convergent development. This feature of convergence has been commented by Nathan Houser, who, in "Peirce's Pragmatism and Analytic Philosophy: Some Continuities" (Houser 2002), shows that Peirce's semiotic is important to understand Analytic Philosophy after the Unity of Science Movement, led by Otto Neurath, Rudolf Carnap and Charles Morris in the late nineteen-thirties. ${ }^{1}$

In this paper I would like to present a discussion of some issues stemming from something that could be regarded as an earlier step in that convergence: similarities in the account of the external world that can be found in both Rudolf Carnap's Der logische Aufbau der Welt ${ }^{2}$ and Clarence Irving Lewis's Mind and the World-Order. Baldwin (2007) presents a brief comparison between Lewis and Carnap, but he takes for that aim another of Carnap's works, The Logical Syntax of Language, published in 1934. Therefore, this paper is also intended to understand the picture in which Baldwin presents his comments. Following that point of convergence, I intend to present some indications for interconnecting Carnap's and Lewis's proposals towards a different approach in philosophy of science.

Principia 18(2): 243-268 (2014).

Published by NEL — Epistemology and Logic Research Group, Federal University of Santa Catarina (UFSC), Brazil. 


\section{The Aufbau project}

The Aufbau is an effort towards the elaboration of a logical-epistemological system in which all objects - understood in a broad sense, as events and concepts alike are constructed out of some fundamental concepts. Carnap took the idea of logical construction from Russell's works; the epigraph of the Aufbau is Russell's supreme maxim of scientific philosophizing: "wherever possible, logical constructions are to be substituted for inferred entities" (Russell [1914] 1959, p.155; Carnap [1928a] 2003, p.5). ${ }^{3}$

This project is regarded by Alberto Coffa as the peak of the logicist program in the philosophical movement which he calls the semantic tradition. This program was in the agenda of authors like Frege, Russell, Helmholtz, Hilbert, Mach, and Bolzano. The aim of logicism, according to Coffa, is to establish opposition to Kantian epistemology by means of elaborating semantic theories in order to rule out the notion of pure intuition from scientific knowledge. The motivation of this project is the fact that Kantian epistemology relies on mental faculties to justify our beliefs; this seems to be a form of psychologism that creates the uncomfortable situation of requiring reference to the 'organs' of the intellect, which cannot be properly (or, scientifically) studied (Coffa 1982, pp.679-85). ${ }^{4}$ Carnap's Aufbau presents a simpler alternative for the epistemological picture of the external world, in which there is no need for transcendental mental faculties or the synthetic a priori - since logical constructions are to be regarded as analytical. Let us see how this construction is carried through.

The fundamental concepts chosen by Carnap are the autopsychological objects, i.e. the psychological occurrences, or elementary experience, of a subject. It is worthy noticing that the terminology chosen by Carnap for such objects is 'elementary experiences' (or, in German, elementar Erlebnisse), and not 'elementary impressions'. Therefore, Carnap is not intending to deal with pure and simple sense-data, such as patches of color, but with objects already constituted in the subject's lived experience, and so, impossible to be analyzed in smaller portions. When Carnap discusses the choice of the autopsychological basis, he explains that what he has in mind as to those objects are perception complexes, like the ones proposed by the Gestalt psychological theory (Carnap [1928a] 2003, pp.98-110)..$^{5}$

Therefore, as Gestalt psychology proposes, the autopsychological domain is composed of objects, insofar as these are distinct from the mere sum of sensory elements. More than that, autopsychological objects, as Gestalt objects, are experiences of structural relations. As an example one can mention the case of a person who listens to a symphony in a certain key, and in other occasion listens again to the same symphony, but this time in a different key. The person is able to recognize the symphony, even though the musical notes to which the person listened are not the 
same in the two cases. What the person was able to recognize was the characteristic structure of that symphony. ${ }^{6}$

The method chosen by Carnap to set up his logical system involved the linguistic expression of those perceived structures. What Carnap proposes in the Aufbau is that statements can be made about certain places in the experience stream - certain portions of experience allow us to make statements about autopsychological objects. And the logical structure of such statements has some relation to the structure of the perceived objects. In possession of such structures of elementary experience, the subject constructs a second level of objects, that of physical objects, the external world. And the physical domain serves as a basis for the construction of other minds, the heteropsychological domain of objects. The next level in Carnap's construction is of cultural objects, which depend on both physical and heteropsychological objects - respectively, documentations and manifestations of cultural objects.

From the logical point of view, ascension and reduction between levels of objects is done linguistically: all statements of a higher level are to be translatable into statements of the immediate inferior level. So, all statements about physical objects must be translatable into statements about autopsychological objects, as well as all statements about heteropsychological objects are to be translatable into statements of physical objects, and all cultural-level statements must be translatable into statements about both physical and heteropsychological objects (Carnap [1928a] 2003, pp.30-97).

This method became known as verificationism, even though this name does not appear in the Aufbau. A statement is verifiable if all objects it deals with can be reduced to autopsychological objects, that is, if the statement can be translated into statements which deal only with autopsychological objects.

Verification can be carried through directly or indirectly according to the level in which the object is found. This means that a statement about a physical object - an object located in space and time - can be translated into statements about autopsychological objects, i.e. statements that present the way that physical object has been experienced by a subject. Accordingly, statements about heteropsychological objects, about other minds, have to be translated into terms of physical objects and the verification process is fulfilled with the possibility of translating these into the autopsychological level. Cultural objects, in contrast, must have their statements translatable into both physical and heteropsychological domains, that is, the verification of cultural objects must relate to the documentations and manifestations of such objects.

The translation process is done by means of translation rules, which are logical constructs, elaborated by means of definitions. In other words, after establishing some definitions, a translation carried through such definitions is to be seen as an analytic procedure, that is, translations do not aggregate meaning to what is trans- 
lated - rather, the translation process is intended to be some sort of clarification of concepts, something to which later Carnap used the term "explication". ${ }^{7}$ This conception of translation as analytic - as well as this conception of analyticity - is result of the development of the semantic tradition (Coffa 1991, chapters 11-14).

The Aufbau presents us a kind of constructional system, in which there is a basis and a method for the ascension to higher levels of knowledge, in a foundationalist fashion. It must be noted, nevertheless, that Carnap's kind of foundational structure is merely formal, as opposed to substantive, or material, foundationalism, in the sense that Carnap admits that the basis may be changed, instead of proposing one firm point upon which the whole construction would depend - like the Cogito in Descartes. Carnap discusses the possibility of choosing the physical or even the heteropsychological object domain as basis for the constructional system. ${ }^{8}$ It is the requirement that there must be such a basis that allows us to label Carnap's position as a kind of foundationalism. ${ }^{9}$ Carnap chooses autopsychological objects as basic because of his aim of reconstructing knowledge as a whole. This choice was subject to much dispute in the Vienna Circle, ${ }^{10}$ and also by the recent tradition of commentary. ${ }^{11}$ But we are not going to discuss this problem in this paper. The important point for us here is to understand that Carnap chose that basis in order to advance his construction of the world, which can be seen as the accomplishment of the logicist program. The Aufbau showed another way for philosophers to understand knowledge without having to refer to metaphysical conditions of possibility. The external world could be understood as a complicated structure of relations of smaller structures, which referred finally to our elementary experience of the world.

This view entails the idea that our knowledge of the external world somehow reflects the structural order of the empirical reality. Therefore, if we understand the meaning of a physical level statement, then we know how such an object can be experienced. If we have any knowledge about mental events of another person, that is because there is some evidence in the person's overt behavior that allows us to construct such a piece of knowledge. If we can say something about a cultural object, say, an institution, then we can mention documentations, physical objects to which such an institution is linked, as well as occurrences in the minds of other people, the manifestations.

This does not mean, though, that Carnap is asserting a kind of realism, in which our knowledge corresponds to reality. Carnap also is not asserting a kind of idealism, in which reality is constructed in the mind. Indeed, he withholds his judgment about both conceptions, proposing that his constructions only show how our knowledge of an empirical reality may be. ${ }^{12}$ In the paper "Pseudoproblems in Philosophy", Carnap presents an illustration of this point. He asks us to imagine two geographers on an expedition the aim of which is to discover whether a certain mountain exists or is only a legend. They locate the mountain and observe its position, shape, height, rock

Principia 18(2): 243-268 (2014). 
composition etc. But one of the geographers is a realist, and says that the mountain they found not only has all the properties they observed, but it is also real, which means that it is supported by something real which they cannot know as it is in itself. The other geographer is an idealist, and disagrees, saying that the mountain is not real, but only their perceptions and states of consciousness. According to Carnap, that metaphysical problem is impossible to solve, since one cannot prove either that one of their positions is true or that one of them is false. And this kind of question is different from the geographical, scientific, matters they were discussing before, in which case they reached a unanimous conclusion. This is the difference between empirical questions and metaphysical questions, in Carnap's view: in all empirical matters, a decisive answer can be obtained, unlike metaphysical pseudoproblems, which can never be settled (Carnap [1928b] 2003, pp.332-4).

Therefore, Carnap's conception of verification has no strong ontological implications. Statements are not to be judged as corresponding or not to a metaphysical reality, but only as agreeing or not with an empirical basis. This is a somewhat instrumentalist point of view, in which our knowledge of the external world is not to be considered as true or false in the traditional correspondence sense of truth, but only as more or less in agreement with one's own experience.

This instrumentalist stance holds also for Carnap's own constructions. As was observed above in this paper, Carnap admits several forms for his system. Hence, for Carnap, there is not just one logical and rational reconstruction which is possible or correct for human knowledge. ${ }^{13}$ Carnap provides as illustration for his idea the case of a railroad map of Eurasia. This map contains no precise information about the distance between one station and another, and it also does not present the names of the stations. The map focuses on the intersections which happen in each station; with this, one can identify some stations just by the position they occupy in relation to other stations and to the amount of intersections that can be found there. Another map may contain the name of the stations, but not all the intersections. The fact is that neither map is completely precise, but in possession of such maps, a person is able to move all across the train lines. Carnap's construction is intended to serve as a map of human knowledge, which is not supposed to be complete and precise, but may allow one to understand certain relations. If more maps are made, our understanding of human knowledge would improve significantly (Carnap [1928a] 2003, pp.25-7).

It is worth remarking that while Carnap's project has this feature of being an alternative to Kantian epistemology, Friedman (1987) shows us that the Aufbau has some interesting similarities with Kant's work. Among such similarities he highlights three: the resemblance of the two projects, as was pointed out above; the indivisible character of the autopsychological objects; and the program for ruling out metaphysical problems. ${ }^{14}$ 


\section{Mind and the World-Order}

The Aufbau was first published in 1928. In the following year, Clarence Irving Lewis published Mind and the World-Order, in which he presented a conception about the external world with a somewhat similar account of experience by means of perception of structures. Lewis's work is not usually recognized as part of the so-called semantic tradition; rather we may understand it as a reassessment of another tradition of criticism of Kantian epistemology - that of Charles Sanders Peirce. ${ }^{15}$

Lewis's book cannot be regarded, however, as the peak of the Peircean tradition - as Coffa regards Carnap's Aufbau in the logicist tradition. Peirce's work embraces many more matters than are presented in Mind and the World-Order. Also, we cannot say that Lewis was entirely apart from the semantic tradition, since he was aware at least of Russell's proposals on the problem of the external world. ${ }^{16}$ And even though it is usually acknowledged that Lewis is one of the first analytic philosophers in the United States, I am going to stress here the pragmatist background that can be found in his work - as stated in the beginning of the present text, our aim is to understand a previous step of that convergence between analytic philosophy and pragmatism which appeared in the late thirties with the Unity of Science Movement.

Peirce's project can be regarded as an attempt to establish an opposition to the intellectualism which stems from Kantian epistemology. ${ }^{17}$ That means that Peirce aims at the same target as does the semantic tradition. But Peirce does not aim at offering a purely logical alternative to that paradigm; rather he puts forward a proposal in which psychology, scientifically understood, plays a very significant role. In his early texts Peirce objects to the faculty of intuition on the grounds that we cannot distinguish in our experience between what is actually perceived and what is inferred. Peirce also opposes the capacity for introspection because of the difficulty we have in telling the difference between what is part of our inner experience and what is part of the external world. Of course there are cases in which such distinctions can be drawn accurately. It is upon these cases that philosophers that sustain those separations rely. Peirce prefers, in turn, to draw attention to the cases in which such differences are not so clear.

Peirce presents some illustrations of such cases: one of them is of a magic trick, in which the spectators have some idea of - or may even know - how the trick is done. But that is an inference, since the audience, supposing that the illusionist did a good job, could not actually see what happened. Another example given by Peirce is that of recollections of dreams: the images seen in dreams are often fragmentary and confused, but we are frequently able to remember them in a coherent and somewhat significant plot, so that we can give an account of what we dreamt (Peirce [1868a] 1992, pp.13-5).

Principia 18(2): 243-268 (2014). 
Hence, the pragmatist framework in which Lewis advances his proposal takes into account the interaction between our experience and the external world, but at the same time this framework considers that the two concepts - experience and world - are also results of that interaction. In other words, it is not possible for us to depart from the interaction between experience and world in order to build an epistemological theory which considers the two elements separately. All we can do in order to understand each concept is to think of them in abstract terms. And the method chosen by Lewis to investigate knowledge, as he says, is "through reflective examination of experience (more particularly of our own part in it or attitude toward it)" (Lewis [1929] 1956, p.13).

Lewis's conception of the knowing process involves on the one hand what is given in experience, and on the other hand the concepts with which we organize our experience and get to know the external world. This may be misunderstood as something similar to Kant's proposal, in which the manifold given in intuition is categorized and organized by the pure concepts of the understanding by means of the synthesis of apprehension. But for Lewis the concepts are not pure in the Kantian sense, for they are acquired through our life and experience. And as such, concepts are subjected to change. They are not fixed "organs" of the mind, as is the understanding in Kantian epistemology. Concepts are logical constructions human beings happen to make so as to order the world. The misunderstanding may grow a little bit by the fact that Lewis considers his concepts to be a priori. However this $a$ priori does not mean that concepts are independent of experience, but just that they are prior to experience, in the sense that the external world as we know depends on this structure of concepts; and such concepts are dependent upon experience in the sense that they are acquired and subjected to change throughout our lives by means of our experience - which is also, itself, conditioned by a priori concepts acquired in an earlier stage of our lives (Lewis [1929] 1956, pp.195-8). These traits allow us to consider Lewis's a priori as pragmatic, that is, as relative to an empirical aspect of language, thought, and signification. ${ }^{18}$

Another aspect of Lewis's conception of a priori concepts is that they are not absolute and fixed, that is, such concepts may change with the acquisition of new knowledge and new experiences, as life progresses. Consequently, a priori concepts also change as a result of actions and interests, insofar as those are closely related to knowledge and experience. That's to say that Lewis adopts a relative concept of the a priori - relative to the prior knowledge and thick experience of the knowing subject. This is significant if we think that what we call 'reality' depends upon a priori concepts. The quality of being 'real', therefore, is not absolute either, being relative to the many contexts in which it is used. In Lewis's terms, 'real' is a word similar to 'useful', so that "nothing is useful for every purpose, and perhaps everything is useful for some purpose" (Lewis [1929] 1956, p.15). Analogously, the concept of 'real' must 
be specified as to the class of things in certain situation which can be called 'real' so that everything else is to be called unreal in that particular situation.

Hence, the external world, according to Lewis, is formed when the chaotic given is subsumed under our a priori concepts. Lewis presents as an example the description of a fountain pen: in making such a description, a person uses some words the meaning of which she learned throughout her life, abstracting the object from the present situation and relating it to streams of her consciousness which are not present experience. For instance, situations in which she used the pen, or the moment when she bought it. Such relations that point beyond present experience reflect, according to Lewis, pieces of knowledge and modes of action apprehended, or acquired, in the same way of the terms used to describe the pen. But the given would be the same were the person a little child or someone who has never seen a fountain pen. The turning point that allows the description to be made as such is the fact that the person has concepts like "cylinder", "hard rubber" and "a poor buy", to which the given is subsumed (Lewis [1929] 1956, pp.49-50). We must notice from the example that concepts may be of physical nature, but also of cultural character, such as "poor buy".

A problem that arises at this juncture is this: if the a priori concepts are developed through our experience, and each human being has a different experience, a different life etc., it is reasonable to say that each human being has a different structure of a priori concepts, and, therefore, has a different external world. In this case, how is communication possible? Lewis answers this by saying that a person's a priori concepts project into the given a structure which is isomorphic to the structure that the other person's concepts project into the given. So, the external world, so to say, of one person is somewhat isomorphic to the external world of the other person. Lewis offers an illustration in which mankind meets some creatures from another planet, say Mars. Supposing that these Martians are not an overwhelmingly superior race that knows everything about us (and speak English), and also that they do not have only destructive intentions (or vice-versa), the only way for communication to be established is by means of the perception of the structure of the Martians' language. The example given by Lewis is a situation in which the humans flash their lights once, and then twice, and then three times, and the Martians answer with four flashes of light. According to Lewis, this means that the Martians have the structure of the natural numbers among their a priori concepts. Humans and Martians are able to communicate in this mathematical context because they share this structure (Lewis [1929] 1956, pp.90-116). We could complement his example by saying that if the Martians flash their light five times instead of four in that case, then it means that they have the prime numbers structure among their concepts, and Humans and Martians can communicate with each other in this prime number context.

This example is too naive and imprecise, but it serves very well as a simplified

Principia 18(2): 243-268 (2014). 
explanation about how communication happens. If one person emits a sign that has such and such structure, we can say that another person understood that sign if she is able to recognize that structure. Misunderstandings arise when this intersubjective isomorphism of structures is not present. This approach to communication may be regarded as emphasizing the syntactical aspect of language - in which signs are related to each other. But we must also take into account that Lewis's proposal involves a conceptual structure that forms the external world, which in semiotic theory would be regarded as semantic.

The above statement has to do with the works of Charles Morris, who proposes a semiotic theory that understands semantics as the area which studies the relation between signs and objects, or the process called signification. A semantical relation as we see it in this paper is a relation which attributes meaning to a certain sign. In the case of Lewis, the semantic relation obtains between language and the conceptual structure, which is the source of signification. ${ }^{19}$ This means, in Lewis's proposals, that when a piece of communication is produced, that is, when a sign is emitted, its intended meaning must be found among the a priori concepts of the communicator. And to say that another person understood the meaning of that piece of communication is to say that the other person was able to connect the sign received with a part of her a priori conceptual structure in the way intended by the communicator.

This conceptual structure evolves with culture and, as such, explains the fact that communication gets harder as cultural differences get larger. Therefore, according to Lewis, in order for communication to happen, there must be a structure which is to be recognized by the parties involved among the conceptual frameworks used. In other words, Lewis is proposing that when one person understands another, it is not the content of the other's cognitions that the person was able to apprehend; rather, it is the conceptual structural meaning (Lewis [1929] 1956, p.80-1). In the fountain pen example, we would not even understand what Lewis was saying if we did not have the concept of fountain-pen, or, at least, the concepts of cylinder, hard rubber or poor buy.

So, Lewis is proposing that in every act of communication - or, more than that, in every act of cognition - there must be a syntax, in the first place, and also a semantical structure to interpret that syntax. This point will be further developed below.

This point of view is very similar to that which we saw in Carnap's Aufbau, since it says that our knowledge of the external world is constructed out of structures of elementary experiences, taken as statements in an autopsychological language, or, in other words, our knowledge can be understood as built out of a syntactical structure. In the Aufbau, as well as in Mind and the World-Order, there is also a semantical claim, which relates the syntax to the content of human experience, in an attribution of signification. But the fact is that to both authors our knowledge 
of the external world is to be regarded as such - as knowledge - because of the recognizable structure it presents and which reports to the world as we know it. In the years that followed the publication of the Aufbau, Carnap worked on the development of a logical syntax, as a tool for the computation of the structure of the world. This syntactical tool Carnap developed can be understood as an abstraction of the formal structure of language that underlies our conception of the external world as shown in the Aufbau.

This syntactical feature of Lewis's proposal owes much to Peirce, who stated that the only kind of thought one can know about is thought by means of signs (Peirce [1868a] 1992, pp.23-4). Peirce says that "a sign, as such, has three references: first, it is a sign to some thought which interprets it; second, it is a sign for some object to which in that thought it is equivalent; third, it is a sign, in some respect or quality, which brings it into connection with its object" (Peirce [1868b] 1992, p.38). When we realize that every thought itself is a sign, we notice that the process of thinking is a process of signifying, as every thought plays the three relations stated by Peirce to other thoughts, which are themselves signs. A consequence of this complicated standpoint is that the process of thinking is to be regarded as a process of communication - in a simplified parlance, every thought is in a communication context in which it is a sign between another thought and an object. ${ }^{20}$

It is possible to regard Lewis's approach to the external world as a reassessment of this proposal, specifically in what regards the first reference of signification in Peirce's above formulation in the following way: every piece of knowledge we have is a thought, or a collection of thoughts, which is, or are, signs to other thoughts which interpret them - these are the concepts. Since we can have no knowledge without concepts, there can be no knowledge which is not relative to the mind.

We have seen so far many features of Lewis's proposals which are similar to Carnap's Aufbau, such as the fact that both authors belong to traditions of opposition to a strict Kantian epistemology and that their proposals agree in what concerns the structural character of our knowledge of the external world. However, there are some differences - which appear if we follow what seems to be the most evident point of contact between the two proposals: the concept of verification.

\section{Carnap and Lewis on verification}

Verification, for Lewis, is a procedure that requires two separate moments in time. A cognition, or belief, can be verified - that is, considered true - by its consistency with other parts of the experience stream. In other words, the truth of a belief has to do with expectations and predictions it allows us to make. If such predictions are right, i.e. if the belief satisfies some anticipation in experience, then that belief 
is verified and can figure in the body of knowledge. Hence, there is the moment of stating a belief and the moment of noticing that it satisfies the anticipation the belief implies. In "Experience and Meaning", Lewis says that "knowing is a matter of two 'moments', the moment of assertion or entertainment and the moment of verification; both of these moments belonging to experience in the generic sense of that word" (Lewis [1934] 1970, p.134). Another important aspect of this conception of verification is that it requires that the possibility of predictions and of satisfying expectations must be extended in time; also, it puts verification in relation to our patterns of action towards the object of knowledge (Lewis [1929] 1956, pp.12039).

This is clearly a version of Peirce's well-known maxim of pragmatism, ${ }^{21}$ which says that our knowledge of an object must be understood as the implications that our act of knowing the object in that way - and not in another way - has in our lives. This is a break with the duality between thinking, or knowing, and acting which is crucial for Kantian philosophy. If a person knows something, then there is certain behavior the person is expected to have, because conceiving that piece of knowledge means to conceive practical bearings that piece of knowledge has, and so, the person should act accordingly.

Lewis's notion of verification may also be traced back to Peirce's conception of reality, as something which is not prior to its opposite: when a person believes that certain state of affairs is real, it must be granted that this person conceives something to be unreal. The idea of reality can only have appeared when that person had a conception about something, and someone, or something else, showed this person that it was wrong, that reality is different from that conception (Peirce [1868b] 1992, p.52). Therefore, in this pragmatist framework, knowledge is necessarily something which can be wrong. The concept of verification in Lewis's proposal takes this sort of fallibilism into account, since knowledge is what can be verified, i.e. what can be confirmed by other parts of the stream of experience. In other words, a piece of knowledge is a conception about something which satisfies this criterion of reality, that is, knowledge is something which survived, or at least potentially survives, the attempts of showing that reality is different from that.

Lewis discusses verification more thoroughly in the paper "Experience and Meaning" written with the objective of establishing a debate with the Vienna Circle. Thus, in that text Lewis criticizes Carnap's verificationism as well as the choice of autopsychological objects as basis for a constructional system of knowledge.

The two criticisms are connected in the sense that in the two moments required for Lewis's verification there is the presence of the a priori concepts: when a belief is entertained, or asserted, it is by means of memory, imagination or whatever that involves a recollection of an object - and such a recollection is made with the concepts; in the moment of proper verification, there is the recognition of the concepts 
in the present experience of the object. In the example of the fountain pen, if a person believes that the mentioned pen is in her drawer, it creates some expectations, anticipations, for instance, that if the person opened the drawer, she would see an object with characteristics that match the description of the pen made by means of those concepts we saw above: cylinder, hard rubber, poor buy, etc. The second moment, that of, so to say, proper verification, is when the person opens the drawer, finds the pen and notices that its features are consistent with the description entertained in the first moment. Therefore, according to Lewis, one cannot think of verification as mere reduction to autopsychological objects since verification refers to concepts which are of diverse nature - as we saw, even concepts which would belong to Carnap's cultural domain, such as "poor buy", play a role in the process.

The concept of a poor buy is of a social and cultural nature and should not be so simply put in terms of one subject's elementary experience. Unless we consider that the subject is already in a social context of communication - something which is not really impossible to figure out, since Carnap talks about Gestalt psychology objects which may be related to cultural contexts, which would hardly appear without communication. This relation between verification and language may be seen as a point of contact between Carnap's and Lewis's proposals and can be further developed, but we are not going to do that in the present text. ${ }^{22}$ As stated above, our aim is to discuss the similarities in their account of the external world.

In the Aufbau, the process known as verification plays the role of a demarcation criterion: any object that cannot be reduced to the elementary experience of a subject is to be considered metaphysical and cannot figure in the body of knowledge and science. In linguistic terms, a (pseudo) statement that cannot be translated into statements about autopsychological objects, either directly or indirectly, is not a genuine statement, as it has no cognitive meaning. The external world is therefore constructed in the Aufbau as an empirical reality and Carnap proposes the suspension of judgment as to any thesis about reality beyond that empirical realm. As we have seen, the metaphysical theses of realism and idealism are to be considered void of meaning, since such theses talk about relations between the empirical reality and some imperceivable substance.

In "Experience and Meaning", Lewis says that a question about reality as independent of what can be known is a meaningless question; in his words, "a relation of experience to what cannot be brought within experience is a relation which cannot be investigated, and one the very conception of which as cognitive involves a confusion of thought" (Lewis [1934] 1970, p.135). This standpoint is taken by Lewis in that text as an important point of departure between his proposal and the logical positivists. But we shall see that it is not quite like that.

Lewis elaborates by pointing out a statement that can be associated to realism, what he calls the realistic hypothesis: "if all minds should disappear from the uni- 
verse, the stars would still go on in their courses". Lewis supposes that the Aufbau system would not consider this as genuine knowledge, for the meaning of a statement about 'star going on in its course' requires that we present an individual's elementary experiences related to that - something which cannot happen in a moment when all minds have disappeared from the universe.

Nevertheless, in Lewis's proposal that statement is verifiable, even though it can never be actually verified: verification, as shown above, involves two moments, one in which the statement is heard, read, or conceived, and a second moment in which we relate other portions of our experience stream to the statement. For example, we relate the statement to other portions of experience by imagining 'star going on in its course' and noticing that such an object does not depend on any mind in the universe; this leads us to assent to the statement, at least for its meaningfulness. In Lewis's phrasing, "imagination is sufficient for empirical meaning, though it requires perception for verification" (Lewis [1934] 1970, p.144).

Consequently, Lewis considers that there must be the possibility of verification in some other moment; even though it is somewhat reasonable to relate all knowledge to first person experience, or to present experience, since we cannot know something with which we had never had contact. Yet in cases that involve only one person, Lewis says that "if, for example, there can be knowledge of a future event in one's own life, then the datum which is the vehicle of this anticipation is not the anticipated cognoscendum". And this is valid for all knowledge to the extent that "all empirical knowing has the dimension of anticipation or implicit prediction, the thing known is not to be identified with, or phrased exclusively in terms of, here-and-now experience" (Lewis [1934] 1970, p.136).

The reply to this point came from Moritz Schlick, another of the leading members of the Vienna Circle. In "Meaning and Verification", Schlick says that though some parts of the Aufbau allow some misunderstandings, the meaning criterion adopted by the logical positivists is the possibility of verification, or verifiability, and not consummate verification; this means that a statement about the future is meaningful, i.e. verifiable, because it can be verified in case we expect some events to happen. More than that, Schlick reminds us that the concept of verification adopted by the Vienna Circle is a logical concept, not an empirical one. In the case of the realistic statement posed by Lewis, verification is warranted because there is the logical possibility of pointing out how 'stars going on in their courses when all minds have disappeared' may be related to elementary experience. The statement is verifiable, but will never be verified - and that would be enough for its meaningfulness (Schlick [1936]).

Carnap mentions Lewis's criticism, as well as Schlick's answer, in the paper "Testability and Meaning". However, Carnap preferred not to insist on the concept of verification: he started working on a new notion, that of confirmation. ${ }^{23}$ Carnap claims to be in agreement with Schlick's defense of verificationism, but since they 
had divergences on some other aspects, it would be better to leave aside the verifiability criterion (Carnap 1936-7, pp.422-4).

As to methodological solipsism, i.e. the requirement of reference to a person's elementary experience, Carnap tells us that when he put forward that proposal, he had in mind just to account for the fact that in empirically testing a statement a person can only refer to her or his own experience. Such a person, Carnap says, "cannot use the results of other people's observations unless he has become acquainted with them by his own observations, e.g. by hearing or reading the other man's report" (Carnap 1936-7, p.424). This standpoint is very reasonable and perhaps even trivial. Nevertheless, if we take a closer look at the question, we may notice that the problem is not methodological solipsism in those terms specified by Carnap, but what has been done with that proposal: analyzing or justifying scientific knowledge as depending on a single individual feels like biting more than one can chew. It is important to remind that Carnap aimed at presenting an incomplete image of knowledge, as the railroad map metaphor illustrates, that is, the image of knowledge presented in the Aufbau is not supposed to be representative of the whole of scientific knowledge, but just one possible glance at it - even though Carnap's constructional system is often mistaken to be intended as a complete reconstruction of science.

The criticism presented by Lewis points out the fact that our own elementary experiences are formed in social situations of communication - from which it is impossible to escape. Therefore, even if we understand other minds as constructions risen from physical objects which are built out of autopsychological objects, we cannot deny that our elementary experience is marked by our interactions with other people and by elements of our culture.

The point of view advanced by Carnap in "Testability and Meaning" goes in a similar direction: he proposed to call a predicate 'observable' to a person if such a person can, with suitable arguments (for example, with a few observations), reach a decision as to accept or reject the predicate (Carnap 1936-7, pp.454-5). Thus, it is considered observable the attribute that an individual, the object of analysis, considers to be observable. So, if a physicist affirms to observe 'presence of electric current' in a certain object, we shall take this attribute as observable in our analysis of that part of scientific language - even though we know that 'electric current' is a theoretical term that depends on a series of cultural elements relative to certain scientific theories and to the communities connected to those theories.

Carnap proposes with his confirmationist criterion of meaning that a sentence is to be considered meaningful if it can be reduced to a class of sentences the predicates of which are observable. The concept of reduction Carnap adopts in "Testability and Meaning" is also different. It is no longer a matter of possibility of translation, but a rather more complicated notion: from the logical point of view, reducing a sentence to another sentence entails establishing some relations of implication among them; 
from the empirical point of view, which some years later Carnap called pragmatic, ${ }^{24}$ saying that a statement is reducible to another one is, roughly speaking, the same as saying that the people involved know how to use the former in function of the latter. Hence, stating that a certain law of physics is confirmable means to state that the physicists know how to use such a law on the basis of their observations; that is, the physicists can organize their experience in function of the law.

There is in "Testability and Meaning" a new treatment to the realistic statement proposed by Lewis, which could be meaningless according to Carnap's old concepts (or to some interpretation of them), "if all minds should disappear from the universe, the stars would still go on in their courses". Carnap says that the behavior of stars, as prescribed by celestial mechanics laws, is independent of the existence of living beings or minds on the universe. Hence, if those laws are confirmed on the basis of current observations, so are the predictions they allow. Therefore, Lewis's realistic statement is confirmable and meaningful, since scientists can predict how stars go on in their courses in a moment when all living beings have disappeared from the universe. The statement would be even testable - as we know what we should do to test it, though, due to a matter of fact, we would not be able to effectively carry out the test (Carnap 1936-7, p.37).

So, as we see, by the late thirties Carnap had taken a different stance regarding the points Lewis had criticized him: Carnap no longer adopted the methodological solipsist strategy and he was not resorting lastly to the experience of one individual in order to account for scientific knowledge. Rather, Carnap was relating the basic terms of his logical analysis to a pragmatic, or empirical, dimension. And, at least in the treatment to the realistic statement posed by Lewis, they came up to the same results.

\section{Lewis and post-Aufbau Carnap}

In the first half of the 1930's, Carnap received many criticisms to the point of view presented in the Aufbau. Most of these came from his colleagues in the Vienna Circle and aimed mainly at his foundationalism and at his methodological solipsism, just like the ones offered by Lewis. The results of Carnap's reaction to those criticisms were presented in The Logical Syntax of Language (Carnap [1934] 2002). After further debates, Carnap advanced his confirmationism. Let us talk a little about Carnap's work in this period in order to improve our understanding of "Testability and Meaning", the text in which Carnap presents some results which are close to the ones found by Lewis.

Between the publication of the Aufbau and that of The Logical Syntax of Language, Carnap held many different positions regarding those points. One of them, presented in the text known as "The Unity of Science" (Carnap [1931] 1995), shows

Principia 18(2): 243-268 (2014). 
physical objects as basis for the system; therefore, without the autopsychological domain and without methodological solipsism. It is worth mentioning that in that text Carnap proposed that scientific hypotheses are justified by their predictive power something which resembles Lewis's concept of verification. Non-hypothetical statements, however, are still justified in a constructionist fashion. In The Logical Syntax of Language, Carnap's standpoint is highly conventionalist: he says that a logical system which aims at a rational reconstruction of science can have many forms, according to the conventions adopted and the aims one has in doing such a reconstruction. This conventionalism is established by Carnap's Principle of Tolerance, which states that philosophers should not prohibit linguistic forms, but set up conventions in order to understand and represent them (Carnap [1934] 2002, pp.51-2).

Thomas Baldwin in his text "C. I. Lewis - Pragmatism and Analysis" presents a comparison between Carnap's point of view in The Logical Syntax of Language and Lewis's proposals in Mind and the World-Order. His point is that Carnap's logical syntax is marked by conventions that stem from the pragmatic dimension, based on his principle of tolerance, generating something which can be called a logical-linguistic version of the picture Lewis elaborated from the point of view of a pragmatist metaphysics and philosophy of mind (Baldwin 2007, pp.189-91). ${ }^{25}$

In 1935 Carnap fled to the United States of America in order to escape the political situation in Europe. He, then, had contact with the pragmatist philosophy, especially through Charles Morris. At that time, Morris was working on a proposal which brought together the logical empiricist and pragmatist traditions from a semiotic standpoint, which he called scientific empiricism. ${ }^{26}$ Carnap adopted scientific empiricism ${ }^{27}$ and advanced the idea that his philosophy of science, which until then was mostly syntax and semantics, had to be complemented by empirical, pragmatic, studies of scientific behavior. This point of view was implicit in The Logical Syntax of Language, since Carnap doesn't specify the nature of the process that leads to the establishment of conventions. ${ }^{28}$

Lewis opposed Morris's proposal, since he found some features of Carnap's logical empiricism very hard to bring into agreement with pragmatism. Besides the matters we have already mentioned, Lewis finds three more problems: the concept of science adopted by the two traditions, the attitude towards metaphysics, and the epistemological status of ethics. Lewis wrote a paper explaining these points in the late thirties (Lewis [1941] 1970), but due to the outbreak of World War II, that paper was only published in 1970, in the Collected Papers of C. I. Lewis. Anyway, in 1941, when the paper was supposed to be published, Carnap had already changed many of his views again. Indeed, Lewis comments on this tendency to change points of view in members of the Vienna Circle; he says that "however admirable this tendency, it makes it necessary for one who would mark them out to aim at a moving target, and be correspondingly doubtful of his accuracy" (Lewis [1941] 1970, p.92). 
In "Experience and Meaning", Lewis considered that in the Aufbau Carnap dealt with all the problems one has to deal in an account on the problem of the external world, but only had taken the wrong course with the methodological solipsistic stance, which invariably leads to the problem of other minds (Lewis [1934] 1970). Therefore, if we focus "Testability and Meaning" we may find an increasing approximation between Carnap and Lewis - especially if we think that Carnap is proposing that observation is conditioned by the cultural background of the observer. Indeed, as Baldwin reminds us, in that paper Carnap stated that his position concerning verification is "in full accordance with Lewis" (Carnap 1936-7, p.426). ${ }^{29}$ This view on verification, that is, on the possibility of reducing knowledge to observable subjectmatter, is the claim that "no complete verification is possible but only a process of gradually increasing confirmation" (Carnap 1936-7, p.425).

But bringing together Lewis's proposals and Carnap's confirmationism is not so simple, since according to Carnap, justification is carried through by the observation level, requiring no recourse to the cultural background - something which seems to be the focus of analysis of Lewis's proposal. There's a difference of emphasis, therefore, but we (just like Carnap did) see no signs of contradiction between the two proposals.

The other three points of disagreement were also revised in later texts, especially during the organization of the International Encyclopedia of Unified Science, a project which counted on collaborations by Carnap, Morris, Dewey and Neurath, among others. The approximation between Carnap and the pragmatist tradition gets stronger from this period on. ${ }^{30}$ What is important to notice, however, is that Carnap did not deal anymore with the problem of the external world - at least not so directly as in the Aufbau.

Since Carnap chose not to deal with the problem of the external world in his post-Aufbau career, one could take Morris's proposal of seeing logical empiricism and pragmatism in a continuum and consider Lewis's Mind and the World-Order as some kind of complement to Carnap's studies in semantics, which started in the 1940's. I don't intend to decide about the feasibility of this enterprise in this text, but it is important to remark that Carnap was taken by his semantical investigations towards the development of a logic of induction; this is also a subject that arises naturally from Mind and the World-Order — indeed Lewis dedicates the eleventh chapter of that book to the consideration of the problems concerning the basis for probability and induction. In this sense, Lewis's work could be viewed as a good candidate for dealing with the metaphysical and methodological problems Carnap left aside in the Logical Foundations of Probability (1962). As Baldwin points out, Carnap's logical systems have their form established by conventions "which perform a role comparable to the a priori principles of Lewis's conceptual schemes" (Baldwin 2007, p.189).

Principia 18(2): 243-268 (2014). 
Another subject that was present in the Aufbau, but not in Carnap's later work, is the epistemological status of values (Carnap [1928a] 2003, pp.233-4). In Schilpp's The Philosophy of Rudolf Carnap, Morris pointed out, in his last attempt to bring Carnap and pragmatism together, that the standpoint on values Carnap advanced in the Aufbau was quite similar to that of Lewis in Analysis of Knowledge and Valuation (Morris in Schilpp 1963, pp.94-5). In his reply to matters of value and ethics, Carnap doesn't give much attention to Lewis or to Morris, or even to his 1928 conception of values, but he says that he thinks that the subject of values should be addressed in a scientific way, as Dewey proposed in his Theory of Valuation (Carnap in Schilpp 1963, pp.1008-9; see Dewey [1939] 1970). The fact is that the theme of values is not really Carnap's cup of tea, since he never elaborated much on the subject. It is, however, a central issue in pragmatism, and Lewis's proposals are no exception, even, although not mostly, in Mind and the World-Order. ${ }^{31}$ The next step in the framework of convergence we are building here should be towards a comparison of Carnap and Lewis on values. ${ }^{32}$

\section{Concluding Remarks}

We have seen that both Carnap (in the Aufbau) and Lewis propose that the external world is construed out of a structure of irreducible pieces of experience. Carnap calls such pieces elementary experiences, or Erlebnisse, and Lewis considers them to be pragmatic a priori concepts. Hence the two authors consider the external world to be built out of structural relations among portions of the given, or of the stream of experience.

In spite of this similarity both authors presented in the last years of the twenties, there is an important difference between the two views. In the Aufbau Carnap is aiming at a justificationist rational reconstruction of human knowledge - so, he focuses on how philosophy can logically understand the ascension from elementary experiences to other kinds of objects. Lewis, on the other hand, aims at providing an explanation for the subsumption of the given under concepts in an intersubjective context of communication. ${ }^{33}$ This difference reflects on the fact the Carnap's construction leads to the problem of other minds, while Lewis's elaboration does not. However, both authors are seeking to avoid recourse to traditional metaphysics, especially to that kind of transcendentalism derived from Kantian philosophy that ultimately relies on the so-called organs of the mind. Carnap replaces such a metaphysics by Gestalt psychology, and Lewis takes the pragmatist context of communication as primitive.

The common result of rejecting that sort of metaphysical strategy is that epistemology no longer offers a complete and all-embracing view of the world. In both 
the Aufbau and Mind and the World-Order, the discussion of the problem of the external world is not guided by the traditional forms of the theses of realism and idealism. As we have seen, Carnap withholds his judgment on that matter, asserting only an empirical reality with no transcendental counterpart, and Lewis presents his concept-relative reality.

After the Aufbau, Carnap did not deal with the problem of the external world anymore. As we have seen, the focus of his philosophy changed towards matters more closely associated to philosophy of science, such as the relation between observations and hypotheses, and the problem of theoretical terms. His proposals also changed, as we have pointed out, in the direction of a more, so to say, objective portrait of knowledge - that is, an image with less phenomenological features than the one presented in the Aufbau. And by the late thirties, we found that Carnap's philosophy, as it gets increasingly more conventionalist, comes to a broad agreement with Lewis's ideas on verification and on the status of reality. At the same time, however, Carnap was not dealing with the metaphysical problems focused by Lewis.

An important feature of Carnap's philosophy, we must remind, is that even though he was all the time changing his position and the focus of his philosophy, it is difficult to find completely incompatible views among his proposals. And this is due to his high degree of conventionalism expressed by the principle of tolerance. In the phrasing presented in the Logical Syntax of Language, Carnap says that "it is not our business to set up prohibitions, but to arrive at conventions (...) everyone is at liberty to build up his own logic, i.e., his own form of language, as he wishes" (Carnap [1934] 2002, pp.51-2). ${ }^{34}$ Under this principle, there is no one correct logical or philosophical approach to science, but always many possibilities, each of them capturing some aspects of the world. We may, therefore, look at the many periods and phases of Carnap's work as different images he was forming of knowledge and science; one of them is the constructional system from the Aufbau; another one is the pragmatic confirmationism in "Testability and Meaning"; still another one is the inductive logic from his later works. Therefore, we may regard the different positions held by Carnap as different portraits of scientific knowledge. In other words, it is not necessary to consider that Carnap radically changed his mind when he put forward confirmationism - he was just presenting another view on the problem - such a view may be better, or more reasonable, in some aspects, of course, but it lacks some features verificationism presented.

This point of view is in some sort of agreement with that present by Alan Richardson in his paper "Carnapian Pragmatism". Richardson sees Carnap as developing tools for science and philosophy of science, in what he calls an engineering philosophy of science (Richardson 2007, pp.311-3). ${ }^{35}$ Richardson argues that this engineering aspect of Carnap's works are deeply entangled with a duality between the theoretical and the practical realms, a reminiscence of Kantian philosophy. Hence, it 
would not be possible for Carnap to be brought together with American pragmatists such as Dewey and Lewis, but, as Richardson notices, there is a Carnapian pragmatism, comparable to that of William James, though. I have argued elsewhere that Carnap's commitment to that Kantian duality may be seen as weaker than it is seen by Richardson. And so, it would be realizable to bring together Carnap and Dewey. ${ }^{36}$

In studying the philosophy of Rudolf Carnap one is frequently confronted with many controversies regarding the different interpretations his philosophy had during 20th Century. The attitude towards such controversies that I have been taking is to consider them as offering tools for philosophers to use in analyzing the world. So, the Kantian Carnap that appears in Friedman's and Richardson's works, for instance, may be of great help in dealing with some problems, but not with some other problems. The same is true about the radical empiricist Carnap that appeared in Ayer's work, ${ }^{37}$ and, why not, the pragmatist Carnap that appears here. This is coherent with Carnap's conventionalist general attitude of seeking to compose an image of knowledge and science which mixes different epistemologies, from various sources. In this sense, Lewis's proposal of the pragmatic a priori may do very well as an image of the external world which can be related to Carnap's confirmationism. For instance, if we are trying to work out the relation between hypothesis and evidence as we see in Carnap's "Testability and Meaning", but we need an answer to the problem of the external world, Lewis offers a good hint. The conventions adopted in the construction of a logical system, in this case, would be correlated to a priori concepts. The same could be done to values, in case the approximation we mentioned above is feasible.

In another paper, ${ }^{38}$ I tried to show that Dewey's pragmatism ${ }^{39}$ may offer many developments which seem to be missing in Carnap's philosophy of science, such as a pragmatic description of scientific laws. Another gap in Carnap's philosophy is a discussion on values - something very common in pragmatist grounds. Bringing all this together may contribute to put Carnap's logical constructions to work, leading us to a thorough and comprehensive view on science developed with the accuracy of logical and mathematical methods. At the same time, such a reunion would enhance pragmatism with a broad variety of logical and mathematical tools, which can be found in the logical positivists' work. In that paper, I have pointed out that pragmatism had a common aim with the Vienna Circle: the improvement of society by means of the enforcement of a scientific attitude among people in general; understanding the continuum between the two schools of thought could help us attain that objective.

Finally, the image of a railroad map presented in the Aufbau suits very well our view in the present paper: not every feature of the tracks is to be represented in the map. On the contrary, in order to attain certain aims, like, say commuter-friendliness, some characteristics of the railroad must be left aside. And since many maps are possible, just as various aims for drawing such a map are admitted and many strate-

Principia 18(2): 243-268 (2014). 
gies for reaching such aims are to be regarded as reasonable, a more adequate understanding of the railway is reached with the interlinked comprehension of many maps.

Therefore, a very fruitful way to look at the odd convergence Carnap and Lewis presented by the late twenties is to see Mind and the World-Order as another map for the same railroad the Aufbau sought to schematize. And the present text may be seen as a sketch towards the junction of the two maps. ${ }^{40}$

\section{References}

Ayer, A. J. 1936. Language, Truth, and Logic. London: Penguin Books.

Baldwin, T. 2007. C. I. Lewis - Pragmatism and Analysis. In: M. Beaney (Ed.) The Analytic Turn. New York: Routledge, pp.178-95.

Carus, A. W. 2007. Carnap's Intellectual Development. In: M. Friedman; R. Creath (Ed.) (2007) pp.19-42.

Carnap, R. 1928a[2003]. The Logical Structure of the World. In: R. Carnap (2003), pp.1300.

—. 1928b[2003]. Pseudoproblems in Philosophy. In: R. Carnap (2003), pp.301-43.

- 1931[1995]. The Unity of Science. M. Black (trans.). Bristol: Thoemmes Press.

- 1934[2002]. The Logical Syntax of Language. A. Smeaton (trans.). Chicago and La Salle: Open Court.

- 1936-7. Testability and Meaning. Philosophy of Science v.3: 420-471; v.4: 01-40.

—. 1950[1996]. Testability and Meaning. 2nd Edition. In: S. Sarkar (Ed.) Logical Empiricism at its Peak. New York and London: Garland, pp.200-65.

- 1961[2003]. Preface to the Second Edition. In: R. Carnap (2003), pp.v-xi.

- 1962. Logical Foundations of Probability. 2nd Edition. Chicago: The University of Chicago Press.

- 2003. The Logical Structure of the World and Pseudoproblems in Philosophy. R. A. George (trans.). Chicago and La Salle: Open Court.

Coffa, A. 1982. Kant, Bolzano, and the Emergence of Logicism. The Journal of Philosophy 79(11): 679-89.

- 1991. The Semantic Tradition from Kant to Carnap: to the Vienna Station. Cambridge: Cambridge University Press.

Cunha, I. F. 2010. Values and Logical Tolerance. Cognitio-Estudos 7(1): 9-18.

- 2011. The pragmatic aspect of scientific laws in Carnap's later proposals. In: L. H. Dutra; A. M. Luz (Eds.) Temas de Filosofia do Conhecimento. Rumos da Epistemologia, v. 11. Florianópolis: NEL/UFSC, pp.310-20.

- 2012. Rudolf Carnap e o Pragmatismo Americano: Ferramentas para a filosofia da ciência. Doctoral Thesis. Philosophy Graduate Program. Florianópolis: Universidade Federal de Santa Catarina.

Dewey, J. 1925[1963]. The Development of American Pragmatism. In: Philosophy and Civilization. New York: Capricorn Books, pp.13-35.

Principia 18(2): 243-268 (2014). 
1938[2008]. Logic: The Theory of Inquiry. The Later Works of John Dewey, v. 12. Carbondale: Southern Illinois University Press.

—. 1939[1970]. Theory of Valuation. In: O. Neurath; R. Carnap; C. Morris (Eds.), pp.379-447.

Dutra, L. H. 2005. Oposições Filosóficas: A Epistemologia e suas Polêmicas. Florianópolis: Editora da UFSC.

- 2008. Pragmática da Investigação Científica. São Paulo: Loyola.

Feibleman, J. 1945. Peirce's Use of Kant. The Journal of Philosophy 42(14): 365-77.

Friedman, M. 1987. Carnap's Aufbau Reconsidered. Noûs 21(4): 521-45.

- 1999. Reconsidering Logical Positivism. Cambridge: Cambridge University Press.

2007. The Aufbau and the Rejection of Metaphysics. In: M. Friedman; R. Creath

(Ed.) pp.129-52.

Friedman, M.; Creath, R. (Ed.). 2007. The Cambridge Companion to Carnap. Cambridge:

Cambridge University Press.

Houser, N. 2002. Peirce's Pragmatism and Analytic Philosophy: Some Continuities. Agora-

Papeles de Filosofía 21(2): 11-32.

Järvilehto, L. 2009. The Pragmatic A Priori of C. I. Lewis. Cognitio-Estudos 6(2): 96-102.

Lewis, C. I. 1929[1956]. Mind and the World-Order. New York: Dover.

—. 1934[1970]. Experience and Meaning. In: Lewis (1970), pp.258-76.

—. 1941[1970]. Logical Positivism and Pragmatism. In: Lewis (1970), pp.92-112.

-1946. An Analysis of Knowledge and Valuation. La Salle: Open Court.

- 1970. Collected Papers of Clarence Irving Lewis. Stanford: Stanford University Press.

Liston, G. 2008. Unidade da Ciência e Tolerância Linguística. Doctoral Thesis. Philosophy

Graduate Program. Florianópolis: Universidade Federal de Santa Catarina.

- 2012. Carnap e o Revisionismo. Principia 16(1): 99-119.

Misak, C. (Ed.). 2004. The Cambridge Companion to Peirce. Cambridge: Cambridge University Press.

Mormann, T. 1996. El Lenguaje en Neurath y Carnap. In: R. Cirera; A. Ibarra; T. Mormann

(Ed.). El Programa de Carnap. Barcelona: Textos de Bronce, pp.215-41.

- 2007. Carnap's Logical Empiricism, Values, and American Pragmatism. Journal of General Philosophy of Science 38: 127-46.

Morris, C. 1937. Logical Positivism, Pragmatism and Scientific Empiricism. Paris: Hermann et Cie Éditeurs.

- 1946[1955]. Signs, Language, and Behavior. New York: Braziller.

Neurath, O.; Carnap, R.; Morris, C. (Ed.). 1955. International Encyclopedia of Unified Science. Chicago: Chicago University Press.

- 1970. Foundations of the Unity of Science: Towards an International Encyclopedia of Unified Science. Volume 2. Chicago: Chicago University Press.

Oberdan, T. 1993. Protocols, Truth and Convention. Amsterdam and Atlanta: Rodopi.

Peirce, C. S. 1868a[1992]. Questions Concerning Certain Faculties Claimed for Man. In:

Peirce (1992), pp.11-27.

—. 1868b[1992]. Some Consequences of Four Incapacities. In: Peirce (1992), pp.28-55.

— 1878[1992]. How to Make Our Ideas Clear. In: Peirce (1992), pp.124-41.

— 1992. The Essential Peirce. Volume 1. In: N. Houser; C. Kloesel (Ed.). Bloomington and Indianapolis: Indiana University Press.

Principia 18(2): 243-268 (2014). 
Pincock, C. 2007. Carnap, Russell, and the External World. In: M. Friedman; R. Creath (Eds.) (2007), pp.106-28.

Reisch, G. A. 2005. How the Cold War Transformed Philosophy of Science. Cambridge: Cambridge University Press.

Richardson, A. W. 1998. Carnap's Construction of the World: the Aufbau and the Emergence of Logical Empiricism. Cambridge: Cambridge University Press.

— 2007. Carnapian Pragmatism. In: M. Friedman; R. Creath (Ed.) (2007), pp.295-315.

Russell, B. 1914[1959]. The Relation of Sense-Data to Physics. In: Mysticism and Logic and Other Essays. London: George Allen \& Unwin, pp.145-79.

Schilpp, P. A. (Ed.). 1963. The Philosophy of Rudolf Carnap. La Salle: Open Court.

- 1968. The Philosophy of C. I. Lewis. La Salle: Open Court.

Schlick, M. 1936. Meaning and Verification. The Philosophical Review 45(4): 339-369.

Short, T. L. 2004. The Development of Peirce's Theory of Signs. In: C. Misak (Ed.) (2004), pp.214-40.

Smith, B. 1998. Gestalt Psychology. In: Routledge Encyclopedia of Philosophy CDRom. London: Routledge.

Skagestad, P. 2004. Peirce's Semeiotic Model of the Mind. In: C. Misak (Ed.) (2004), pp.24156.

Uebel, T. 2007. Carnap and the Vienna Circle: Rational Reconstrutionism Refined. In: M. Friedman; R. Creath (Eds.) (2007), pp.153-75.

Westphal, K. R. 2010. Kant's Critique of Pure Reason and Analytic Philosophy. In: P. Guyer (Ed.) The Cambridge Companion to Kant's Critique of Pure Reason. New York: Cambridge University Press, pp.401-30.

IVAN FERREIRA DA CUNHA

State University of Maringá (UEM)

Federal University of Santa Catarina (UFSC)

Brazil

clockwork.ivan@gmail.com

Resumo. Este artigo compara as propostas sobre nosso conhecimento do mundo exterior apresentadas por Rudolf Carnap, no livro conhecido como Aufbau, com aquelas de Clarence Irving Lewis em Mind and the World-Order. Tal comparação é feita em termos da oposição à epistemologia kantiana estabelecida pelos dois livros; o Aufbau é visto como o ápice da tradição logicista e Mind and the World-Order é tomado em continuidade com o pragmatismo. Nota-se que os dois livros apresentam o conhecimento do mundo exterior como uma consequência de uma organização estrutural da experiência humana. Entretanto, há um importante ponto de divergência: o conceito de verificação que cada autor adota é diferente, e tal conceito foi até tema de discussão entre Lewis e o Círculo de Viena. O presente artigo mostra tal discordância, mas também mostra como Carnap mudou seu ponto de vista na década seguinte à publicação do Aufbau, em direção a uma posição que é bem mais próxima das ideias de Lewis. Em tal processo, no entanto, Carnap mudou seu foco e não lidou mais com o problema do mundo exterior. Este artigo também procura chamar atenção para algumas características da relação entre Carnap e a tradição pragmatista que só recentemente começaram a atrair interesse.

Palavras-chave: Carnap; Lewis; logicismo; pragmatismo; problema do mundo exterior.

Principia 18(2): 243-268 (2014). 


\section{Notes}

${ }^{1}$ See the texts by those authors in Neurath; Carnap; Morris (Ed.), (1955). See also, for a historical and political assessment of the movement, Reisch (2005).

${ }^{2}$ Henceforth: Aufbau. I use here the English translation, The Logical Structure of the World (Carnap [1928a] 2003).

${ }^{3}$ On the relationship between Carnap and Russell, see Pincock (2007).

${ }^{4}$ A more thorough presentation of the semantic tradition is in Coffa (1991).

${ }^{5}$ See Friedman (2007), pp.133-7, for more details on the autopsychological basis.

${ }^{6}$ For more information about Gestalt psychology and epistemology, see Smith (1998). Lewis discusses Gestalt psychology in relation to values in An Analysis of Knowledge and Valuation (Lewis 1946, especially chapter XVI), but I am not going to discuss such matters here.

${ }^{7}$ See Carnap [1961] 2003, p.v, the preface to the second edition of the Aufbau.

8 The only objection Carnap raises has to do with the establishment of cultural objects as the basis. He supposes that with such a basis the construction of physical objects would be difficult, if not impossible (Carnap [1928a] 2003, pp.94-5). However, in Dutra 2008, chapter 6 , the cultural basis is shown to be possible, and even more expedient for certain ends, such as the comprehension of intentionality.

${ }^{9}$ For a more thorough discussion of this point, see Dutra 2005, chapters 2 and 3, and Cunha 2012, chapter 1 .

${ }^{10}$ Good sources for those debates are Oberdan (1993), and Mormann (1996).

${ }^{11}$ Friedman (1999) and Richardson (1998) consider that there is no foundationalism in the Aufbau. They oppose the traditional way of reading Carnap, that stems from Quine, Goodman, and Ayer (See Friedman 2007, pp.138-42, for a brief recollection of that). Liston (2008) and (2012) surveys the debate, and his interpretation is assumed here: there is no complete foundationalism in the Aufbau, only what Dutra (2005) and (2008) calls a formal one; but Carnap assumes a full-fledged fallibilist stance afterwards; this, however, does not entitle us to draw a hard-and-fast line separating two distinct periods in Carnap's work, since there are theses that persist, e.g. the unity of science.

12 It seems to be possible to find in the Aufbau both realist and idealist elements, even though Carnap declares he is not to be committed to any of those metaphysical stances. For discussion about this controversy, see Coffa 1991, chapter 11.

${ }^{13}$ For the concept of rational reconstruction, see Uebel (2007).

${ }^{14}$ In a recent paper, Friedman also points out that in the Aufbau Carnap assumes a form of transcendental idealism (Friedman 2007, pp.138-42). This, however, does not change our point here, since Friedman's Carnap, just like Kant, is still against the traditional forms of realism and idealism, claiming only the empirical realm to be the source of genuine knowledge.

${ }^{15}$ Pragmatism, as well as Carnap's project in the Aufbau, can be viewed in simultaneous relations of opposition and continuity with the Kantian project in the Critique of Pure Reason. We are not going to present here a complete comparison of the two approaches. A thorough survey of similarities and differences between Peirce and Kant can be found in Feibleman (1945); between Lewis and Kant, see Westphal (2010) and also the chapter by L. W. Beck in Schilpp (1968). The present view of pragmatism in continuity and opposition to the Kantian tradition stems from Dewey ([1925] 1963).

Principia 18(2): 243-268 (2014). 
${ }^{16}$ As evidence that Lewis was aware of Russell's proposals, but that he can be also understood as belonging to the pragmatist family, see the footnotes in Lewis [1929] 1956, pp.15; 64-5.

${ }^{17}$ At least in his early writings, see Peirce ([1868a] 1992), and ([1868b] 1992).

${ }^{18}$ For a more thorough characterization of Lewis's conception of a priori, see Järvilehto (2009).

${ }^{19}$ We must bear in mind however that Morris's semiotic is not equivalent to Peirce's semiotic. Our use of Morris's concepts here is intended to simplify the similarity between Carnap and Lewis. For Morris's Semiotic, see Morris ([1946] 1955).

${ }^{20}$ Peirce's semiotic had many important developments after 1868 , but we are not going to discuss this here. Good sources to understand that development, and also for a better understanding of what is presented here, are Short (2004), and Skagestad (2004).

${ }^{21}$ In Peirce's works there are many versions of that maxim; the most famous is probably the one in Peirce [1878] 1992, p.132.

${ }^{22}$ It is important to remark, however, that this communication contextual interpretation of Carnap's Aufbau is not in perfect accord with the mainstream traditions of reading Carnap. Language is taken to be a computational device in Carnap's proposals, but this does not forbid us to think otherwise, since conventionalism is the main feature of Carnap's ideas. Hence, since methodological solipsism would then vanish, it might lead to a different way to look at knowledge from a Carnapian (even though, perhaps, not Carnap's) perspective. But I am not developing this point of view in this paper.

${ }^{23}$ Some authors (Popper, for example) contend that confirmation was just a relaxed version of verification. Carnap would rather say that there are important differences between the two concepts, such as the fact that confirmation does not involve translation. For Popper's point of view, as well as Carnap's reply, see the respective papers in Schilpp (1963).

24 See the later edition of "Testability and Meaning", Carnap [1950] 1996, p.209.

${ }^{25}$ This is precisely the same point of similarity that Richardson (2007, pp. 307-8), finds between Carnap and Lewis.

${ }^{26}$ Morris published some papers in the mid-thirties on this subject; these were collected in Morris (1937).

27 This seems to have happened at least in 1936. See footnote 2 in Carnap 1936-7, p.422.

${ }^{28}$ Coffa discusses this glimpse of pragmatism in The Logical Syntax of Language in the chapter 18 of his book (Coffa 1991, pp.348-53). See also, Reisch 2005, especially chapters 1, 2 and 16.

${ }^{29}$ Carnap mentions "Experience and Meaning" as a source for Lewis's view on verification.

${ }^{30}$ Some of the characters of Carnap's relation with pragmatism are more deeply discussed in Cunha (2012). The debate between Morris and Carnap in Schilpp's The Philosophy of Rudolf Carnap is a good source to understand how Carnap's view on those topics evolved (see Schilpp 1963).

${ }^{31}$ See Lewis [1929] 1956, p.145, as well as appendixes B and C.

32 This was pointed out by Mormann (2007).

${ }^{33}$ Friedman (1999) claims that there is no justificationist aim in the Aufbau. Uebel (2007, p.157), seems to disagree. Pincock (2007) advances that, under Friedman's criteria, there is no justificationism in Russell's method of analysis either. I do not intend to enter such a debate in the present paper. But briefly: if Carnap rules out metaphysics because it does not 
fit the constitutional system, then fitting such a system seems to be a criterion for some sort of justification - and hence the problem lays on what concept of justification that is. Lewis's proposal can be seen as a justificationist rational reconstruction as well, but of a kind that differs from those present in Carnap's and Russell's works.

${ }^{34}$ Liston (2012) points out that the principle of tolerance is already present in the Aufbau, although not explicitly stated. This is reasonable, since, as we saw, in the Aufbau, logical systems can be built in many ways, being judged by their expediency.

${ }^{35}$ Carus (2007) also exhibits that point of view.

${ }^{36}$ See Cunha 2012, pp.155-63, and also Cunha (2010).

37 See Ayer (1936).

38 See Cunha (2011).

${ }^{39}$ As in Dewey ([1938] 2008) and ([1939] 1970), for example.

40 The author is currently a postdoctoral researcher at the Philosophy Graduate Program of the State University of Maringá (UEM, Paraná, Brazil). This paper, however, was written during the author's doctoral course at the Federal University of Santa Catarina (UFSC, Brazil, 2008-2012) and, more precisely, during a research stage at the University of Pennsylvania, USA, with a CAPES/PDEE grant (2010-2011). But the paper was finished afterwards, during the author's postdoctoral period at UFSC's Núcleo de Epistemologia e Lógica (NEL) with a CNPq/PDJ grant (2012-2014). Therefore, this paper was elaborated with the support of CAPES, and finished with the support of CNPq; both are Brazilian federal agencies concerned with the development of science, technology, and superior education. The author would like to thank his supervisors Luiz Henrique Dutra (UFSC) and Gary Hatfield (Penn) for their attention to this paper.

Principia 18(2): 243-268 (2014). 